\title{
SISTEM INFORMASI KERAJINAN LUKISAN KACA DESA NAGASEPAHA BERBASIS WEB
}

\author{
Oleh \\ I Nyoman Yoga Setyawan, Ni Wayan Marti \\ Jurusan Manajemen Informatika, FTK, UNDIKSHA
}

\begin{abstract}
ABSTRAK
Sistem informasi kerajinan lukisan kaca Desa Nagasepaha berbasis web ini merupakan salah satu pemanfaatan teknologi komputer sebagai media pembelajaran yang lebih mudah dan cepat dimengerti. Sistem informasi ini membahas tentang informasi yang berhubungan dengan lukisan kaca Desa Nagasepaha yang terdiri dari beberapa bagian seperti: kategori serta produk lukisan kaca Desa Nagasepaha, bahan, alat, proses pembuatannya, dan keterangan-keterangan lainnya yang berhubungan dengan kerajinan lukisan kaca Desa Nagasepaha. Sistem informasi ini diimplementasikan dengan menggunakan script PHP dibantu dengan Adobe Dreamweaver CS3 sebagai editor, MySQL sebagai pengelola basis data, Adobe Photoshop CS3 sebagai pengelola design, dan Adobe Flash CS3 Proffesional sebagai pengelola animasi. Dengan demikian Sistem informasi kerajinan lukisan kaca Desa Nagasepaha berbasis web ini diharapkan dapat mempermudah masyarakat dalam mencari informasi yang berhubungan dengan lukisan kaca Desa Nagasepaha dan dapat mempermudah masyarakat untuk melakukan pembelian produk yang dihasilkan.
\end{abstract}

Kata-kata kunci : Sistem informasi, lukisan kaca, Desa Nagasepaha, web

\begin{abstract}
This information system of Nagasepaha's glass painting based web is an advantage of IT as a learning media that make easily and knowledgeable. This information system discuss all about the information that conducted to glass painting of naga sepaha village. The information contain many parts such as the products and categories, materials, tools, the process and also the other explanation related to the Nagasepaha's glass painting. This information system is applied by using php script helped by Adobe Dreamweaver CS33 as editor, MySQL as base data organizer, Adobe Photoshop CS33 as a design organizer, and Adobe Flash CS3 Professional as an animation organizer. So that, information system of Nagasepaha's glass painting based web is expected to make easier for the reader in finding information related to this glass painting. This information is also expected to make easier in doing transaction of this products.
\end{abstract}

Keywords: Information system, glass painting, Nagasepaha Village, web.

Sistem Informasi Kerajinan Lukisan Kaca...........( I. N. Y. Setyawan \& N. W. Marti) 


\section{PENDAHULUAN}

Desa Nagasepaha adalah sebuah Desa terletak di Kecamatan Buleleng, Kabupaten Buleleng yang memiliki kekhasan seni rupa Bali yaitu seni kerajinan lukisan kaca. Umumnya suatu lukisan dituangkan pada media kertas, kanvas, papan, triplek, dan sebagainya. Lukisan di Desa Nagasepaha dituangkan pada media kaca bening oleh Jro Dalang Diah yang menjadi pelukis kaca khas Bali pertama di Bali pada tahun 1927 (Sidhi, 2004). Lukisan kaca di Desa Nagasepaha memiliki tiga macam tema yaitu tema klasik kontemporer, dan modern. Awalnya lukisan kaca Nagasepaha hanya bertema klasik yang mencantumkan cerita-carita pewayangan seperti cerita Mahabarata dan Ramayana yang dapat membentuk dan menguatkan karakter budaya yang bernuansa Hindu. Seiring dengan perkembangan yang terjadi di masyarakat, pengrajin lukisan kaca di Desa Nagasepaha mengembangkan tema yang lebih modern yang memiliki nilai identitas tersendiri dibanding tema umum yakni cerita pewayangan.

Berdasarkan hasil wawancara pada tanggal 20 September 2011 dengan bapak Ketut Santosa seorang pengrajin generasi ke-III dari Jro Dalang Diah mengatakan bahwa penyebaran informasi dan pemasaran lukisan kaca yang dibuat masih dilakukan secara manual serta memanfaatkan media cetak surat kabar atau majalah lokal dan pameran, sehingga tidak banyak masyarakat yang tahu lukisan kaca di Desa Nagasepaha ini. Padahal lukisan kaca Desa Nagasepaha merupakan lukisan kaca khas Bali pertama terdapat di Bali yang masih berkembang hingga sekarang. Bapak Ketut Santosa berharap agar lukisan kaca Desa Nagasepaha dapat diketahui oleh masyarakat secara luas untuk memperluas area pemasaran.

Berdasarkan uraian di atas, pemanfaatan media teknologi sangat diperlukan. Internet adalah suatu media teknologi yang berkembang saat ini. Dengan pengenalan serta pemasaran melalui internet setidaknya dapat menarik minat masyarakat, karena informasi ditampilkan bukan hanya sekedar teks biasa melainkan perpaduan teks, gambar, dan video atau dapat juga disebut dengan web. Oleh karena itu, perlu dibuatkan sistem informasi kerajinan lukisan kaca berbasis web untuk membantu meningkatkan penyebaran informasi dan meningkatkan area pemasaran kerajinan lukisan kaca ini kepada masyarakat secara luas. Web ini 
diharapkan dapat membantu melestarikan seni budaya Bali melalui lukisan-lukisan yang sangat menonjolkan seni budaya Bali itu sendiri. Sistem informasi berbasis web ini juga nantinya dapat membantu mempermudah masyarakat melakukan pemesanan yaitu pemesanan secara online tanpa harus datang secara langsung ke tempat pengrajin lukisan kaca di Desa Nagasepaha.

\section{METODOLOGI PENELITIAN}

Metode penelitian merupakan metode yang akan digunakan dalam pembuatan perangkat lunak, yaitu dalam pembuatan sistem informasi kerajinan lukisan kaca Desa Nagasepaha berbasis web. Dalam pembuatan sistem informasi kerajinan lukisan kaca Desa Nagasepaha berbasis web ini, penulis menggunakan model proses atau jalan yang akan digunakan dalam pembuatannya.

Model proses merupakan peta jalan (roadmap) yang sangat berguna bagi perekayasa perangkat lunak untuk menghasilkan produk yang berkualitas tinggi. Ada banyak model proses yang ada, yang masing-masing memiliki kelebihan dan kekurangan (Kertiasih, 2008).

Model Proses yang digunakan pada pembuatan sistem informasi ini menggunakan model proses Waterfall. Model ini adalah model klasik yang bersifat sistematis, berurutan dalam membangun software dan merupakan model utama dari banyak model. Model ini disebut Waterfall (Air terjun) karena diagram proses tahapannya mirip dengan air terjun yang bertingkat yang terdiri dari 5 tahapan utama diantaranya : Analisis Kebutuhan Sistem, Perancangan Desain, Implementasi (Koding), Testing (pengujian), dan Perawatan. Gambar di bawah ini merupakan gambar dari ilustrasi tahapan model proses waterfall. 


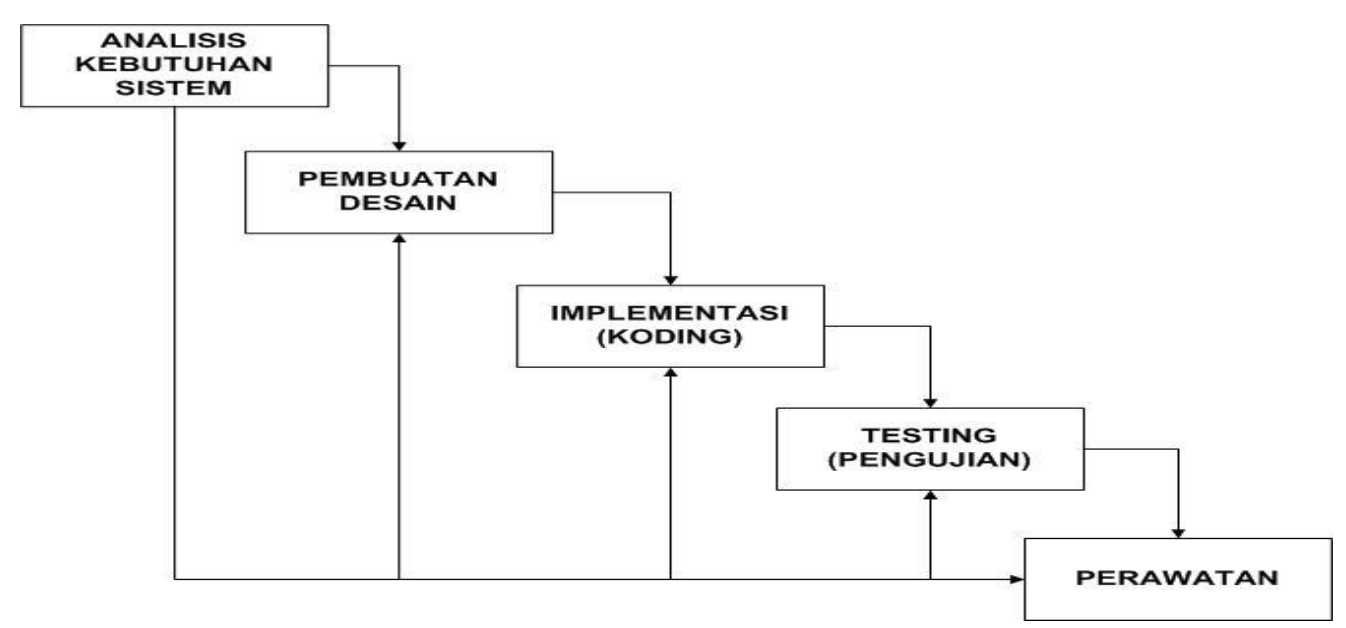

Gambar 1. Gambar Tahapan Model Proses Waterfall

Berikut merupakan penjelasan dari tahapan model proses waterfall.

\section{$\checkmark \quad$ Pembuatan Desain}

Tahapan pembuatan Desain ini dilakukan apabila data-data yang diperlukan sudah di analisis dan sudah sesuai dengan apa yang di butuhkan dalam pembuatan sistem informasi kerajian lukisan kaca Desa Nagasepaha berbasis web ini. Pembuatan Desain dapat berupa rancangan antarmuka.

\section{$\checkmark \quad$ Implementasi (pembuatan koding)}

Pada tahapan ini dilakukannya pengkodingan. Pengkodingan atau pembuatan sintak harus sangat cermat dan teliti agar produk yang di buat dapat cepat selesai. Dalam pengkodingan bahasa pemrograman yang digunakan yaitu $P H P$ dan $M Y S Q L$ sebagai pengelola basis data.

\section{$\checkmark \quad$ Pengujian atau Testing}

Tahap pengujian dilakukan setelah tahap pengkodingan selesai. Tahap ini dilakukan guna menguji produk yang telah dibuat apabila terjadi kesalahan atau dalam pengujian menemukan kesalahan akan kembali ke tahap sebelumnya menurut kesalahan yang di temukan. Misalnya ditemukan kesalahan Desain yang kurang 
tepat, kita bisa kembali ke tahap perancangan Desain begitu juga dengan kesalahan pada pengkodingan kita bisa kembali ke tahap implementasi.

\footnotetext{
$\checkmark \quad$ Perawatan / Maintenance

Perawatan pada produk yang sudah jadi sangat penting agar produk yang sudah jadi ini tidak mengalami kerusakan dan selalu di update. Perawatan suatu produk diperlukan, termasuk di dalamnya adalah pengembangan, karena produk yang dibuat tidak selamanya hanya seperti itu. Ketika dijalankan mungkin saja masih ada error kecil yang tidak ditemukan sebelumnya, atau ada penambahan fitur yang belum ada pada produk tersebut. Pengembangan diperlukan ketika adanya perubahan dari eksternal perusahaan seperti ketika ada pergantian sistem operasi, atau perangkat lainnya.
}

\section{HASIL DAN PEMBAHASAN}

\subsection{Rancangan Sistem}

Rancangan sistem merupakan gambaran awal dari sistem yang akan dibuat. Pada rancangan sistem akan terlihat alur atau proses yang terjadi pada sistem. Rancangan sistem informasi kerajinan lukisan kaca Desa Nagasepaha berbasis web ini terdapat tiga pengguna yaitu admin, pengunjung, dan member. Proses yang terjadi pada sistem ini adalah pengelolaan informasi tentang kerajinan lukisan kaca Desa Nagasepaha dan pengelolaan pemesanan oleh admin, pengunjung melihat informasi yang telah dikelola oleh admin dan daftar member, dan member melakukan pemesanan lukisan melalui halaman member.

Pemecahkan permasalahan dalam perancangan sistem informasi kerajinan lukisan kaca Desa Nagasepaha berbasis web ini menggunakan suatu kerangka pemecahan masalah yaitu dengan diagram uses case.

Use case diagram menggambarkan fungsionalitas yang diharapkan dari sebuah sistem. Sebuah use case merepresentasikan sebuah interaksi antara aktor dengan sistem. Dalam notasi use case, pengguna sistem disebut dengan aktor. Seorang aktor adalah sebuah entitas manusia atau mesin yang berinteraksi dengan sistem untuk melakukan pekerjaan-pekerjaan tertentu. Use case diagram dapat 
sangat membantu dalam menyusun requirement sebuah sistem, mengkomunikasikan rancangan dengan client, dan merancang test case untuk semua feature yang ada pada sistem. Sebuah use case dapat meng-include fungsionalitas use case lain sebagai bagian dari proses dalam dirinya. Secara umum diasumsikan bahwa use case yang di-include akan dipanggil setiap kali use case yang meng-include dieksekusi secara normal (Abdul Kholik, 2007). Gambar di bawah ini merupakan diagram use case dari sistem informasi kerajinan lukisan kaca Desa Nagasepaha berbasis web.

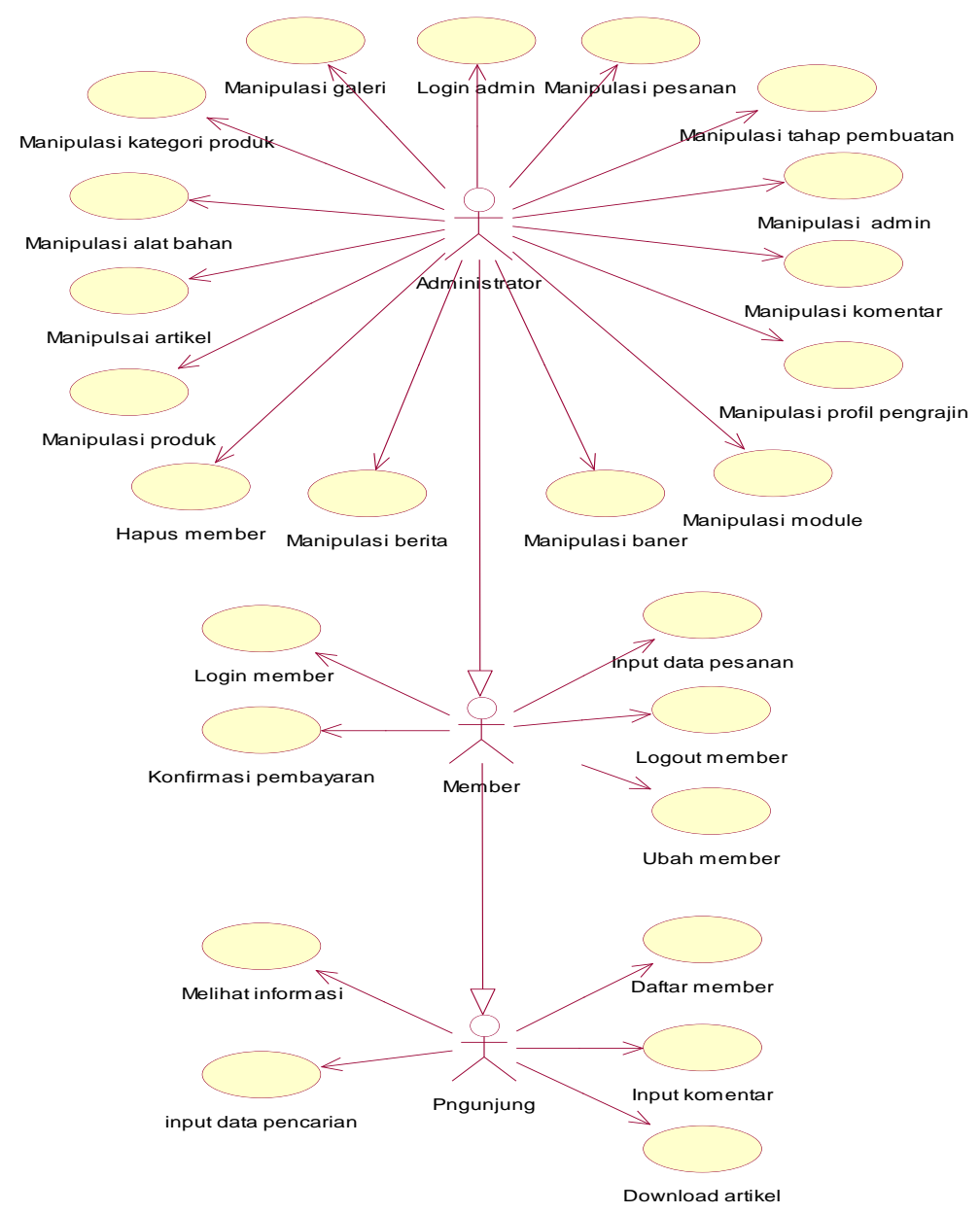

Gambar 2. Diagram Use Case Sistem Informasi Kerajinan Lukisan Kaca Desa Nagasepaha Berbasis Web 
Dari gambar di atas dapat dijelaskan sebagai berikut: Pengunjung dapat melakukan lihat informasi, mengisi komentar, dan melakukan pendaftaran sebagai member; Member dapat melakukan pemesanan secara online dan dapat melakukan aktivitas yang dilakukan oleh pengunjung; Administrator dapat melakukan pengelolaan data yang ada pada sistem informasi kerajinan lukisan kaca Desa Nagasepaha berbasis web dan juga dapat melakukan seluruh aktivitas yang dilakukan oleh pengunjung dan member.

\subsection{Implementasi Sistem}

Sistem informasi berbasis web merupakan sebuah sistem informasi yang mampu menyediakan informasi yang bermanfaat bagi penggunanya. Lebih tepatnya sebuah sistem yang terintegrasi antara manusia dengan mesin, untuk menyediakan informasi yang mendukung operasi atau manajemen dalam suatu organisasi. Informasi ini diterjemahkan ke dalam bahasa mesin dengan output berupa website yang kemudian ditempatkan dalam suatu alamat atau domain di internet. Tujuan pokok dari sistem informasi berbasis web adalah mengolah data untuk menghasilkan informasi sehingga perlu didukung oleh elemen-elemen yang terdiri dari perangkat keras, perangkat lunak dan tenaga pengunjung (Saputro, 2007).

Sistem informasi kerajinan lukisan kaca Desa Nagasepaha berbasis web merupakan sebuah sistem informasi yang menginformasikan tentang hasil produksi kerajinan lukisan kaca Desa Nagasepaha, Kabupaten Buleleng, Bali. Website ini menyediakan fasilitas pemesanan online bagi pengunjung yang sudah terdaftar sebagai member. Pengunjung web dapat melihat produk hasil produksi kerajinan lukisan kaca Desa Nagasepha yang dilengkapi dengan nama produk, ukuran, harga dan bahan deskripsi dari masing-masing produk.

Sistem informasi kerajinan lukisan kaca Desa Nagasepaha ini memiliki beberapa fitur yang dapat diakses oleh pengunjung, yaitu beranda yang berisi tentang lukisan kaca Desa Nagasepaha dan artikel terkait dengan lukisan kaca, produk berisi tentang daftar produk yang dihasilkan oleh pengrajin lukisan kaca Desa Nagasepaha yang terdapat pada menu kiri, profil yang memaparkan tentang sekilas profil dari pengrajin lukisan kaca Desa Nagaspaha, alat dan bahan yang 
memaparkan informasi alat dan bahan yang digunakan pada proses pembuatan, proses yang memaparkan tahapan proses pembuatan lukisan kaca beserta videonya, peta lokasi merupakan gambar peta lokasi pengrajin lukisan kaca Desa Nagasepaha, berita yang memaparkan berita-berita yang berhubungan dengan lukisan kaca Desa Nagasepaha, galeri yang berisi tentang foto kegiatan atau event yang berhubungan dengan kerajinan lukisan kaca Desa Nagasepaha, buku tamu merupakan form yang akan diisi oleh pengunjung untuk berkomentar, dan daftar member merupakan form pendaftaran bagi pengunjung yang ingin menjadi member yang terdapat pada menu kiri.

Sistem informasi ini terdiri dari menu atas, menu kiri, dan konten. Menu atas berisi tentang menu utama website. Pada menu kiri berisi pencarian informasi,menu produk, login member, dan berita produk terbaru. Sedangkan pada konten terdapat informasi yang isinya telah disesuaikan dari masing-masing menu yang telah tersedia pada website.

Antarmuka sistem informasi kerajinan lukisan kaca Desa Nagasepaha terdiri dari 2 antarmuka utama, yaitu antarmuka administrator dan antarmuka user. Gambar 5 dan Gambar 6 merupakan tampilan antarmuka halaman admin dan user dari sistem informasi kerajina lukisan kaca Desa Nagasepaha berbasis web.

JPTK, UNDIKSHA, Vol. 10, No. 2, Juli 2013 : 61 - 72 


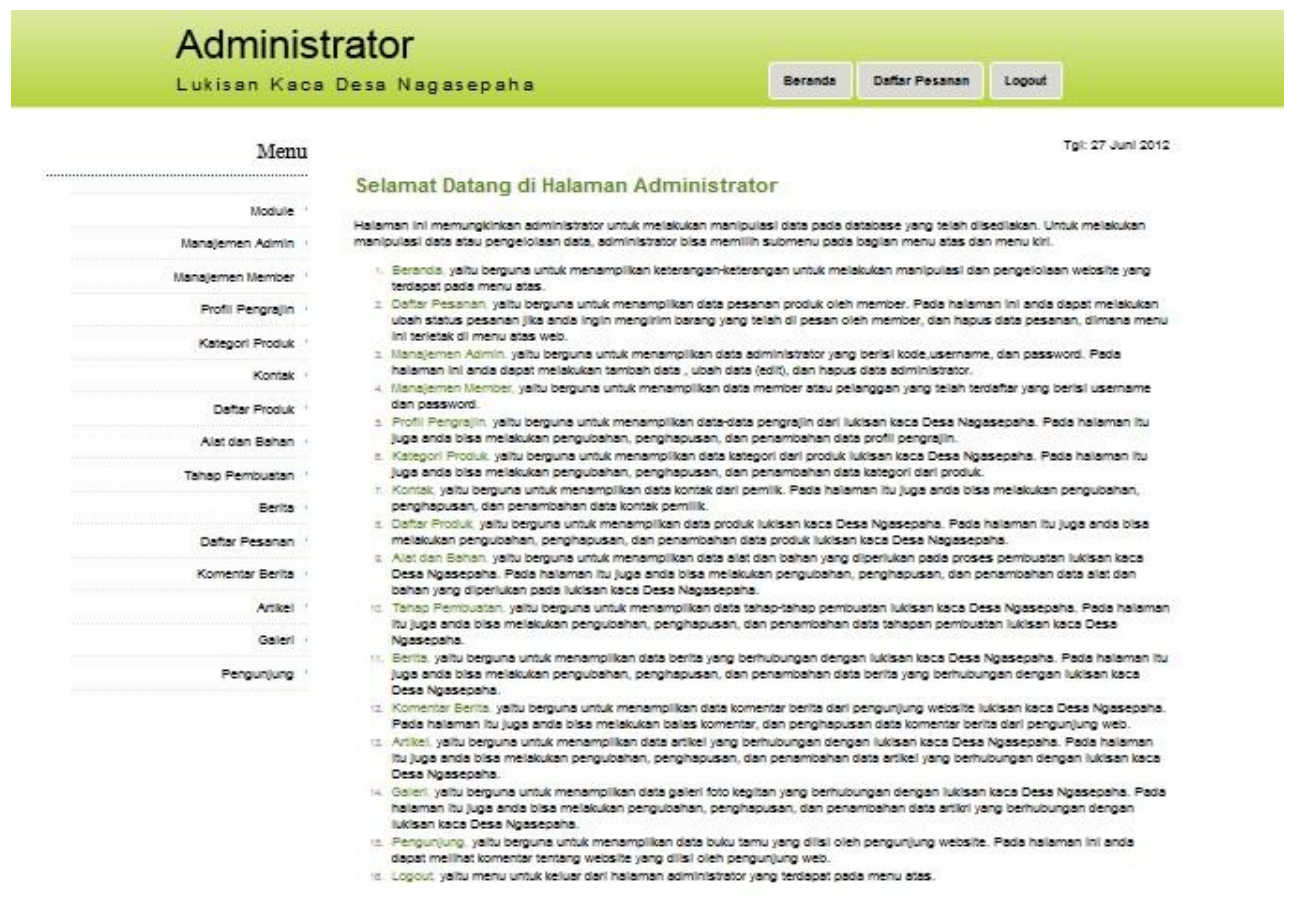

Gambar 3: Gambar Antarmuka Halaman Utama Admin

Halaman administrator merupakan tampilan dari halaman administrator pada web kerajinan lukisan kaca Desa Nagasepaha. Halaman administrator akan muncul apabila telah melakukan login sebagai administrator. Pada halaman administartor, administrator dapat melakukan pengelolaan data dengan memilih menu yang telah tersedia.

Sistem Informasi Kerajinan Lukisan Kaca..........( I. N. Y. Setyawan \& N. W. Marti) 


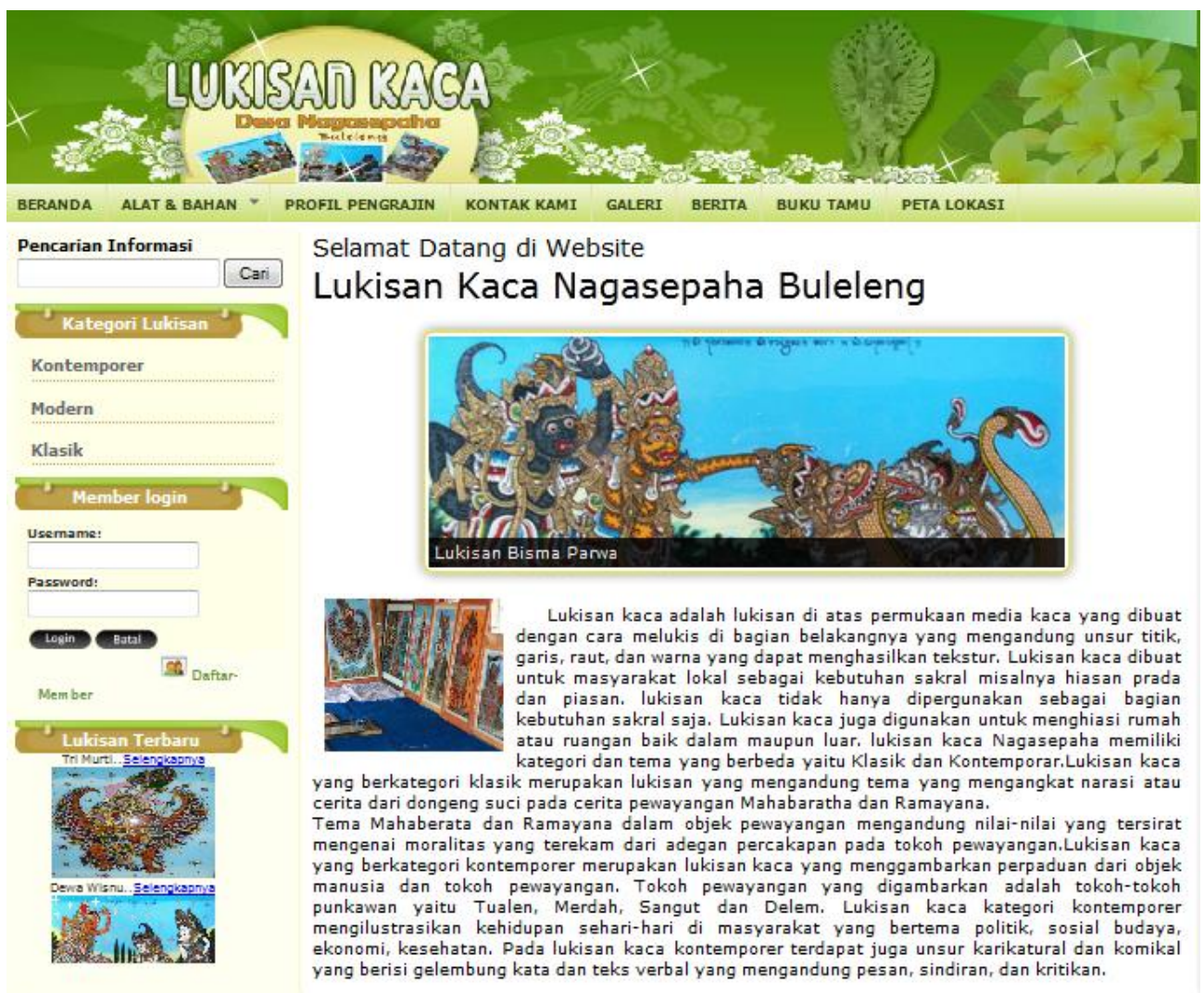

Pengunjung

\section{$\begin{array}{lllllll}0 & 0 & 9 & 5 & 0 & 3\end{array}$}

$\$$ Harrinl : 1
$\$$ Total : 39
$\$$ Hits : 105
$\$$ Total Hits : 9503
\$ Pengunjung: 1

\section{Kalender}

\begin{tabular}{|r|r|r|r|r|r|r|}
\hline \multicolumn{7}{|c|}{ Jual 2012} \\
\hline NG & Sn & S1 & No & Non & Jim & 50 \\
\hline 1 & 2 & 3 & 4 & 5 & 6 & 7 \\
\hline 8 & 9 & 10 & 11 & 12 & 13 & 14 \\
\hline 15 & 16 & 17 & 18 & 19 & 20 & 21 \\
\hline 22 & 23 & 24 & 25 & 26 & 27 & 28 \\
\hline 29 & 30 & 31 & & & & \\
\hline & & & & & \\
\hline
\end{tabular}

\section{Artikel Terkait}

\section{Ketrampilan Glass Painting (lukis kaca), Pembuatan Lukisan Kaca,}

Salah satu ketrampilan yang mendapatkan antusias yang sangat baik adalah ketrampilan Glass Painting (lukis kaca). Ketrampilan yang menggunakan bahan dasar dari kaca sebagai media lukis atau mewarnai ini mempunyai nilai artistik atau nilai seni yang dapat di jadikan hiasan... Selenqkapnya

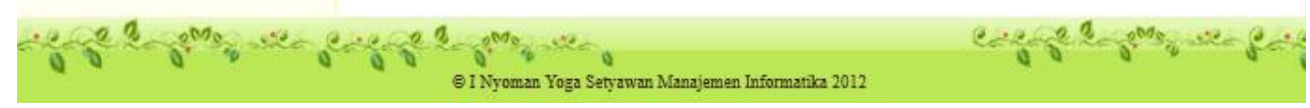

Gambar 4: Gambar Antarmuka Halaman Utama Pengunjung 
Pada bagian paling atas terdapat header web, di bawah header web terdapat menu atas yang terdiri dari beranda, alat dan bahan yang terdapat submenu, profil pengrajin, kontak kami, galeri, berita, bukutamu, dan peta lokasi. Selanjutnya di bawah menu atas terdapat tampilan slider foto, dan menu menu kiri yang terdiri dari pencarian informasi, menu produk, berita produk terbaru, dan konten yang merupakan tempat tampilnya informasi yang telah dipilih melalui link-link yang tersedia pada website.

\section{PENUTUP}

Berdasarkan pembahasan di atas, dapat disimpulkan sistem informasi kerajinan lukisan kaca Desa Nagasepaha dikembangkan untuk membantu menginformasikan, mempromosikan, dan memasarkan hasil produksi kerajinan lukisa kaca Desa Nagasepaha kepada masyarakat Bali pada khususnya. Sistem informasi kerajina lukisan kaca Desa Nagasepaha berbasis web ini dibangun dengan menggunakan beberapa rancangan yaitu rancangan sistem, rancangan basis data dan rancangan antarmuka. Dalam merancang sistem digunakan bahasa pemodelan UML, antara lain use case, diagram aktivitas, diagram sequence, dan diagram class. Fiturfitur yang terdapat pada sistem informasi ini, yaitu menu utama terdapat pada bagian atas, terdapat pemesanan online untuk member, dan sistem informasi ini memiliki 2 halaman utama, yaitu user dan administrator. Sistem informasi kerajinan lukisan kaca Desa Nagasepaha ini menggunakan 3 aktor, yaitu admin sebagai pengelola data website, member merupakan pengunjung yang telah mendapatkan hak akses untuk melakukan pemesanan produk yang sudah ditentukan pada halaman prosuk di web secara online, dan pengunjung sebagai pengguna pertama yang hanya dapat melihat informasi, melakukan pengisian komentar, dan melakukan pendaftaran sebagai member.

Berdasar simpulan di atas, dapat disarankan bagi pembaca dan peneliti yang nantinya ingin mengembangkan agar sistem ini dapat menangani pemesanan produk yang cakupannya lebih luas, dan dapat menangani pemesanan produk sesuai keinginan gambar yang dikirimkan oleh member (anggota) untuk dilukis pada media 
kaca, sehingga member (anggota) tidak harus terpaku pada gambar yang telah dipasarkan pada web.

\section{DAFTAR PUSTAKA}

Kertiasih, Ni Ketut. 2008. Rekayasa Perangkat Lunak. Diktat Kuliah (tidak dipublikasikan). Jurusan Manajemen Informatika UNDIKSHA.

Kholik, Abdul. 2007. "Makalah Analisis dan Perancangan Sistem II Use Case Diagram". Terdapat pada : http://ikyoesan.awardspace.com/tugas/T02_c.pdf (Diakses pada tanggal 03 Agustus 2011).

Saputro, Hendra W. 2007. "Pengertian Website dan Unsur-unsurnya". Terdapat pada: http://www.balebengong.net/topik/teknologi/2007/08/01/pengertianwebsite-dan-unsur-unsurnya.html (Diakses pada tanggal 17 September 2011).

Sidhi, Ipong Purnama. 2004. Pameran Lukisan di Atas Kaca Tradisi dan Perkembangannya. Jakarta: Bentara Budaya Jakarta.

JPTK, UNDIKSHA, Vol. 10, No. 2, Juli 2013 : 61 - 72 